\title{
BMJ Open Socioeconomic deprivation and survival after stroke in China: a systematic literature review and a new population-based cohort study
}

\author{
Ruoling Chen, ${ }^{1,2}$ Zhi Hu, ${ }^{1}$ Ruo-Li Chen, ${ }^{3}$ Dongmei Zhang, ${ }^{1,2}$ Long Xu, ${ }^{1}$ \\ Jingjing Wang, ${ }^{1} \mathrm{Li} \mathrm{Wei}^{4}$
}

To cite: Chen $\mathrm{R}, \mathrm{Hu} \mathrm{Z}$, Chen R-L, et al.

Socioeconomic deprivation and survival after stroke in China: a systematic literature review and a new population-based cohort study. BMJ Open 2015;5: e005688. doi:10.1136/ bmjopen-2014-005688

- Prepublication history and additional material is available. To view please visit the journal (http://dx.doi.org/ 10.1136/bmjopen-2014005688).

\section{The study was orally} presented in Asia Pacific Stroke Conference, Hong Kong, 30 August to 1 September 2013.

Received 23 May 2014 Revised 17 December 2014 Accepted 29 December 2014

CrossMark

For numbered affiliations see end of article.

\section{Correspondence to} Professor Ruoling Chen; r_chen@hotmail.com or Dr Li Wei; I.wei@ucl.ac.uk

\section{ABSTRACT}

Objective: To assess the association of socioeconomic deprivation (SED) with survival after stroke in China.

Design: A systematic literature review and a new population-based cohort study.

Setting and participants: In urban and rural communities in Anhui, China, 2978 residents aged $\geq 60$ years took part in baseline investigation and were followed up for 5 years; five published studies were identified for a systematic review.

Primary and secondary outcome measures: 167 of 2978 participants (5.6\%) had doctor-diagnosed stroke at baseline or 1 year later. All-cause mortality in the follow-up.

Results: In the Anhui cohort follow-up of 167 patients with stroke, 64 (38.3\%) died. Multivariate adjusted hazard ratio (HR) of mortality in patients with educational level of less than or equal to primary school was 1.88 (95\% Cl 1.05 to 3.36) compared to those having more than primary school education. Increased HR of mortality in patients living in a rural area was at borderline significant $(1.64,0.97$ to 2.78), but the HR in patients with lower levels of occupation and income was not significant. Published studies showed a significant increase in stroke mortality in relation to some SED indicators. Pooled relative risk (RR) of mortality in patients with low education was 3.07 (1.27 to 7.34), in patients with low income 1.58 (1.50 to 1.65$)$ and in patients living in rural areas 1.47 (1.37 to 1.58$)$.

Conclusions: The evidence suggests the presence of a mortality gradient after stroke for material as well as social forms of deprivation in China. Inequalities in survival after stroke persist and need to be taken into account when implementing intervention programmes.

\section{INTRODUCTION}

Each year more than six million people worldwide die from stroke, with about $90 \%$ of these deaths occurring in low and middle income countries (LMIC). The number of

\section{Strengths and limitations of this study}

- The main contribution of this study lies in what it tells us about the impact of socioeconomic deprivation (SED) on survival after stroke in China-the most populous nation with the largest number of patients with stroke in the world.

- A new population-based cohort study and a systematic literature review and meta-analysis were run to determine the impact of SED on survival after stroke.

- Mortality after stroke was examined in relation to various indicators of SED, which were grouped for a meta-analysis.

- The number of studies examining the association of SED with survival after stroke in China was not large, and data that could be utilised for meta-analysis were limited, particularly when pooling data based on one of each SED indicator.

- Some participants in the cohort studies were lost to follow-up, which may introduce bias.

- There are lack of data to examine the impact of SED on mortality after haemorrhage stroke.

stroke deaths has been predicted to increase over the next decade by $12 \%$ globally, and by $20 \%$ in LMIC. ${ }^{1}$ Previous studies ${ }^{2}$ suggested that patients with stroke with socioeconomic deprivation (SED) have a significant increase in mortality. Knowledge about the impact of SED on stroke survival is predominately derived from studies undertaken in highincome countries, ${ }^{23}$ with consequential problems in generalising findings to LMICs. This has raised an important question about tackling inequalities in survival after stroke globally. China is the biggest LMIC in the world. It has the largest number of patients with stroke and deaths in the world. Over the past 30 years it has observed an increase in socioeconomic inequality. ${ }^{4}$ However, the impact of SED on survival of Chinese people with stroke is unclear. In this study, we 
examined data from the Anhui cohort study of patients with stroke and carried out a systematic literature review and meta-analysis to assess the association of SED with survival after stroke in China.

\section{METHODS}

\section{The Anhui cohort study}

The methods of the Anhui cohort study have been fully described previously. ${ }^{5-7}$ In brief, we randomly selected 1810 people aged $>65$ years who had lived for at least 5 years in Yiming subdistrict of Hefei city in 2001, and 1709 aged $>60$ years from all 16 villages in Tangdian district of Yingshang county in 2003. In total 3336 older adults participated in the study, of whom 1736 were urban participants, with a response rate of $94.8 \%$. The participants were interviewed by a trained survey team from Anhui Medical University. Permission for interview and written informed consent were obtained from each participant and if that was not possible, from the closest responsible adult. Refusals were respected. The main interview materials were a general health and risk factors record, which was derived partly from the MRC-ALPHA study ${ }^{8}$ and the Scottish MONICA surveys, ${ }^{9}$ and the Geriatric Mental State (GMS) questionnaire. ${ }^{8}$ In the general health and risk factors record we documented details relating to sociodemography, social networks and support, cardiovascular disease (CVD) and other risk factors, and doctor-diagnosed diseases. ${ }^{6}$ Using the GMS interview data and the Automated Geriatric Examination for Computer Assisted Taxonomy (AGECAT) ${ }^{8}$ we diagnosed depression and dementia for each participant. According to standard procedures, ${ }^{9}$ we measured systolic and diastolic blood pressure, weight and waist circumferences for all participants (wave 1). One year after the baseline investigation we re-examined 2608 cohort members (wave 2) using the same protocol as in the baseline. ${ }^{8}$ The cohort members who were not re-interviewed consisted of 84 older adults who died before wave 2 interview, 19 of whom were terminally ill, 115 who moved house due to residential area development and completely lost contact, 381 who were away to visit friends/relatives or who stay with their children's family, and 116 who refused to be re-interviewed. From November 2007 to March 2009, we contacted those surviving cohort members for wave 3 interview and identified all deaths. ${ }^{7}$ Ethical approval for the study was obtained from the Anhui Medical University and the Research Ethics Committee, University College London.

\section{Socioeconomic status and SED}

In this study, we measured SED using four different indicators, including educational level, occupational class, income and rural-urban living. ${ }^{7}$ In the interview we asked each participant whether he or she attended any school or not, if yes they answered 'yes' they would then be asked to specify either (1) primary school, (2) secondary school, (3) high secondary school/professional school or (4) university/college. The question/answers are validated in urban as well as rural participants. ${ }^{5}{ }^{6}$ Participants' occupational class was determined as 'nonmanual' or 'manual' from their main job titles as an officer/teacher, businessman, manual worker, peasant, housewife or other. All participants were required to provide the answers 'very satisfied', 'satisfied', 'average' or 'poor' to the question of 'Are you satisfied with your income?' and the answers 'yes' or 'no' relating to having experienced a financial problem in the last 2 years. ${ }^{6}$ An expert panel estimated the annual income for each category of these answers; participants who had a 'poor' income or had a serious financial problem in the past 2 years were categorised to have $<¥ 1000$ per month in family capital. We considered all participants who lived in rural areas as having a separate indicator of SED compared to their urban counterparts. Apart from their low incomes, they had lower levels of education and occupation. ${ }^{6}$ In this study we further defined participants who had levels of education less than or equal to primary school and manual occupational class or family income $<¥ 1000$ permonth as having SED.

\section{Baseline stroke and follow-up mortality}

At baseline interview, we asked each participant (or their carers if the participant was unable to answer) whether he or she had received a doctor's diagnosis of stroke, any types of heart disease, angina, diabetes or other chronic condition. At wave 2, we used the same protocol to record stroke cases as the baseline. Previous studies showed that self-reported doctor's diagnosis of stroke was validated in older adults. ${ }^{10}$ We monitored vital status of the cohort members up to 1 December 2008. We visited the local residential areas to obtain information about participants' survival status through resident committees, family members, neighbours and friends. In the urban cohort, we also reviewed electronic registration databases from the Centre for Disease Control and Police Registration in Hefei city to identify mortality and causes of deaths. In total, $89.2 \%$ of the urban cohort members and $89.3 \%$ of the rural had vital status data available.

\section{Statistical analysis}

Apart from patients with stroke documented at wave 1 survey we included all patients with stroke identified at wave 2 survey for analysis, which increased statistical power. We examined distributions of baseline risk factors between stroke and non-stroke older adults using one-way analysis of variance for continuous variables and the $\chi^{2}$ test for categorical variables. We employed multivariate adjusted Cox regression models to calculate HR of 5-year mortality and its 95\% CIs among patients with stroke compared to those participants with non-baseline stroke. The adjusted variables were age, sex, body mass index (BMI), smoking status, alcohol drinking, marital status, living alone, urban-rural, educational level, occupational class, income, hypertension, 
hypercholesterolemia, diabetes, angina, depression and dementia. To examine the impact of SED on stroke mortality, we analysed data from each of the SED indicators, respectively, compared with those participants without stroke. To strengthen comparability of rural and urban data, we censored the urban cohort follow-up to 1 December 2006, which gave a 5-year follow-up periodsimilar to that in the rural cohort. We computed follow-up time of the cohort members from the baseline interview to the end of follow-up or date of deaths. We calculated a ratio and its $95 \%$ confidence intervals (CIs) of HRs in patients with versus without SED. ${ }^{11}$

\section{Systematic literature review and meta-analysis}

We extensively searched Chinese literature electronic databases, including China National Knowledge Infrastructure (CNKI), China Biological Medicine Database (CBMDISK), WANFANG and Chongqing VIP to identify Chinese papers eligible for inclusion in this review. The primary search terms included variations on the nomenclature of (1) 'stroke' (or 'cerebrovascular accident', 'cerebrovascular disorders', 'cerebral hemorrhage', 'subarachnoid hemorrhage', 'intracranial hemorrhage'), (2) 'survival' (or 'mortality') and (3) 'socioeconomic status' (or 'poverty', 'education', 'income', or 'occupation', 'rural'). We also searched PubMed, Scopus and Web of Science to identify any publications in English on the topic, where additional key words of 'China' or 'Chinese' were used. Titles and abstracts were read and screened for original studies relating to the association between SED and stroke survival. We manually searched the bibliographies of selected papers for any additional studies. The literature search was covered from 1966 (the earliest year in those datasets) to 30 August 2013. Studies were included in this review if they quantified the relationship between any measure of SED and survival after stroke. In the systematic review, we defined stroke cases as those which were diagnosed according to WHO criteria based on overt symptoms and covertly using neuroimaging techniques. We excluded those studies which examined mortality due to stroke on a population level, ${ }^{12}$ rather than in patients with stroke. Online supplementary figure S1 for schematic presentation of identifying articles for review. PRISMA guidelines for systematic literature reviews were followed. For five eligible papers the following data were extracted independently by two reviewers: the first author, year and place of study, the study design, sampling of participants, SED measurement, stroke diagnosis criteria, characteristics of patients, follow-up duration and rate, and relevant statistical findings. We reviewed each of the studies according to standard procedures that we have used before. ${ }^{13}{ }^{14}$ Using a modified version of the Newcastle-Ottawa criteria, ${ }^{15}$ we reviewed these articles for quality (see online supplementary table S1). We pooled mortality data from the Anhui cohort and other studies identified, in relation to different SED variables, according to the methods we used in previous studies. ${ }^{13} 14$ If heterogeneity of within-study and between-study variation in those selected studies was significant, a random effect model was used; otherwise, a fixed effect model was used.

All analyses in this study were performed in the STATA statistical package (Window V.11.2, STATA Corporation, College Station, Texas, USA).

\section{RESULTS}

The Anhui cohort study

Of 3336 participants, $2978(89.3 \%)$ were followed up over 5 years (median year of follow-up was 5.2). We documented 167 patients with stroke at baseline (42 from wave 2 survey). Their average age was 73.4 $(\mathrm{SD}=7.0), 53.9 \%$ were women and $52.7 \%$ were illiterate. Compared to participants without stroke, they were older and more likely to live in an urban area, live with somebody, drink less alcohol and have higher levels of hypertension, hypercholesterolemia, angina, heart disease, diabetes, depression and dementia diagnoses (table 1). There were no significant differences between the two groups in terms of gender, levels of education, occupation and income, BMI, and smoking status.

During the follow-up, 565 cohort members died: 64 deaths occurring in patients with stroke $(38.3 \%)$ and 501 in participants without stroke(17.8\%). After adjustment for age, sex, BMI, educational level, occupational class, income, urban-rural, living alone, smoking status, alcohol drinking, marital status, hypertension, hypercholesterolemia, diabetes, angina and depression/ dementia, HR for 5-year mortality in patients with stroke compared to participants without stroke was 1.91 (95\% CI 1.45 to 2.52 ).

Table 2 shows numbers and percentages of mortality among patients with stroke with and without SED, and participants without stroke. We found that compared to those who had no stroke at baseline, patients with stroke with low levels of education, occupation and income or rural living had a significant increase in mortality (multivariate adjusted HRs were around 2.30, respectively), while patients with stroke without SED had no significant increase in mortality (table 2 ).

Data analysis within patients with stroke further showed an association of SED with mortality. Ratio of HRs for mortality between patients with versus without SED indicated that low education significantly increased mortality after stroke. Increased HR of mortality in patients living in a rural area was at borderline significant (ratio of HRs=1.64, 0.97 to 2.78), but HR in patients with lower levels of occupation and income was not significant (table 2).

\section{Literature review}

Table 3 shows the characteristics of five studies. ${ }^{16-20}$ All except one ${ }^{19}$ are from large cities in China. The studies covered populations of patients with stroke from 1984 to 2005. In 1998, Wu et $a l^{16}$ published data of the Sino- 
Table 1 Sociodemographic and clinical characteristics of participants with and without stroke at baseline in the Anhui cohort study, China

\begin{tabular}{|c|c|c|c|c|c|}
\hline \multirow[b]{2}{*}{ Variable } & \multicolumn{2}{|l|}{ Stroke } & \multicolumn{2}{|c|}{ Non-stroke } & \multirow[b]{2}{*}{ p Value } \\
\hline & $\mathrm{n}=167$ & $(\%)$ & $\mathrm{n}=\mathbf{2 8 1 1}$ & $(\%)$ & \\
\hline \multicolumn{6}{|l|}{ Age (years) } \\
\hline Mean (SD) & 73.4 & $(7.0)$ & 71.7 & (6.9) & 0.002 \\
\hline \multicolumn{6}{|l|}{ Sex } \\
\hline Women & 90 & 53.9 & 1456 & 51.8 & 0.598 \\
\hline Men & 77 & 46.1 & 1355 & 48.2 & \\
\hline \multicolumn{6}{|l|}{ Body mass index $(B M I)\left(\mathrm{kg} / \mathrm{m}^{2}\right)$} \\
\hline \multicolumn{6}{|l|}{ Cut-off point } \\
\hline$\leq 25$ & 112 & 67.1 & 1958 & 69.6 & 0.718 \\
\hline $26-29$ & 48 & 28.7 & 759 & 27.0 & \\
\hline$\geq 30$ & 7 & 4.2 & 94 & 3.3 & \\
\hline \multicolumn{6}{|l|}{ Socioeconomic status } \\
\hline \multicolumn{6}{|l|}{ Educational level } \\
\hline College & 19 & 11.4 & 275 & 9.8 & 0.512 \\
\hline High secondary school & 19 & 11.4 & 379 & 13.5 & \\
\hline Secondary school & 26 & 15.6 & 377 & 13.4 & \\
\hline Primary school & 15 & 9.0 & 355 & 12.6 & \\
\hline Illiterate & 88 & 52.7 & 1425 & 50.7 & \\
\hline \multicolumn{6}{|l|}{ Main occupation } \\
\hline Officer/teacher & 17 & 10.2 & 225 & 8.0 & 0.330 \\
\hline Business/other (house wife) & 56 & 33.5 & 873 & 31.0 & \\
\hline Manual labourer & 26 & 15.6 & 374 & 13.3 & \\
\hline Peasant & 68 & 40.7 & 1339 & 47.7 & \\
\hline \multicolumn{6}{|l|}{ Annual income* } \\
\hline High $^{\star}$ & 94 & 56.3 & 1422 & 50.6 & 0.152 \\
\hline Low $^{*}$ & 73 & 43.7 & 1389 & 49.4 & \\
\hline \multicolumn{6}{|l|}{ Urban/rural } \\
\hline Urban & 103 & 61.7 & 1446 & 51.4 & 0.010 \\
\hline Rural & 64 & 38.3 & 1365 & 48.6 & \\
\hline \multicolumn{6}{|c|}{ Social network and support and mental status } \\
\hline \multicolumn{6}{|c|}{ Marital status } \\
\hline Married & 126 & 75.4 & 2036 & 72.4 & 0.696 \\
\hline Never married/divorced & 6 & 3.6 & 115 & 4.1 & \\
\hline Widowed & 35 & 21.0 & 660 & 23.5 & \\
\hline \multicolumn{6}{|l|}{ Living with } \\
\hline Somebody & 158 & 94.6 & 2506 & 89.1 & 0.026 \\
\hline Alone & 9 & 5.4 & 305 & 10.9 & \\
\hline \multicolumn{6}{|c|}{ Cardiovascular risk factors and mental status } \\
\hline Smoking & & & & & \\
\hline Never-smoking & 86 & 69.4 & 1420 & 60.0 & 0.063 \\
\hline Ex-smoking & 10 & 8.1 & 172 & 7.3 & \\
\hline Current-smoking & 28 & 22.6 & 273 & 32.7 & \\
\hline Alcohol drinking in the last 2 ye & & & & & \\
\hline No & 158 & 94.6 & 2258 & 80.3 & $<0.001$ \\
\hline Yes & 9 & 5.4 & 553 & 19.7 & \\
\hline Hypertension (blood pressure & $\mathrm{n} \mathrm{Hg}$ or $\mathrm{t}$ & nyperte & & & \\
\hline No & 46 & 27.5 & 1194 & 42.5 & $<0.001$ \\
\hline Undetected hypertension & 40 & 24.0 & 903 & 32.1 & \\
\hline Untreated hypertension & 12 & 7.2 & 153 & 5.4 & \\
\hline Uncontrolled hypertension & 47 & 28.1 & 438 & 15.6 & \\
\hline Controlled hypertension & 22 & 13.2 & 123 & 4.4 & \\
\hline Hypercholesterolaemia & & & & & \\
\hline No & 143 & 85.6 & 2625 & 93.4 & $<0.001$ \\
\hline Yes & 24 & 14.4 & 186 & 6.6 & \\
\hline Angina & & & & & \\
\hline No & 154 & 92.2 & 2750 & 97.8 & 0.001 \\
\hline Yes & 13 & 7.8 & 61 & 2.2 & \\
\hline
\end{tabular}


Table 1 Continued

\begin{tabular}{|c|c|c|c|c|c|}
\hline \multirow[b]{2}{*}{ Variable } & \multicolumn{2}{|l|}{ Stroke } & \multicolumn{2}{|c|}{ Non-stroke } & \multirow[b]{2}{*}{ p Value } \\
\hline & $\mathrm{n}=167$ & $(\%)$ & $\mathrm{n}=\mathbf{2 8 1 1}$ & $(\%)$ & \\
\hline \multicolumn{6}{|l|}{ Heart disease } \\
\hline No & 130 & 77.8 & 2410 & 85.7 & 0.005 \\
\hline Yes & 37 & 22.2 & 401 & 14.3 & \\
\hline \multicolumn{6}{|l|}{ Diabetes } \\
\hline No & 150 & 89.8 & 2659 & 94.6 & 0.010 \\
\hline Yes & 17 & 10.2 & 152 & 5.4 & \\
\hline \multicolumn{6}{|l|}{ GMS-AGECAT diagnosis } \\
\hline 'Well' & 98 & 58.7 & 2118 & 75.3 & $<0.001$ \\
\hline Depression-subcase & 11 & 6.6 & 93 & 3.3 & \\
\hline Depression-case & 18 & 10.8 & 110 & 3.9 & \\
\hline Dementia-subcase & 16 & 9.6 & 291 & 10.4 & \\
\hline Dementia-case & 24 & 14.4 & 199 & 7.1 & \\
\hline
\end{tabular}

MONICA study of 1984-1993, including approximately 700000 urban and rural residents aged 25-74 years in Beijing. The data showed that a relative risk (RR) of 1-year mortality among patients with stroke living in rural versus urban areas was 1.09 in 1984, and 1.36 in 1993, respectively. ${ }^{16}$ The authors did not report actual numbers of deaths and patients with stroke or $95 \%$ CIs for RR. This prevented us from using the findings for a meta-analysis. Sun et $a l^{17}$ examined 28-day mortality among 13556 patients with stroke, who were derived from parts of the Sino-MONICA study of the population aged 35-74 from 1984 to 2000 in Beijing. Patients living in rural areas had a $47 \%$ increase in mortality compared to their urban counterparts. The study includes a large number of patients with stroke. Although differences in mortality between rural and urban areas were adjusted for age, other factors such as sex were not. These two studies were from Beijing - the capital of China, and only reported rural-urban differences as an SED indicator (table 3).

In 2001 Sheng et $a l^{19}$ followed up 131 ischaemic patients with stroke for 5 years. In a univariate analysis, they observed an association between low income and increased mortality. In a stepwise multivariate regression analysis the income variable could not be entered because it was not significant enough for staying in the model compared to other factors. In 2005, Liu et $a l^{18}$ carried out a retrospective study, collecting data of 485 ischaemic patients with stroke admitted between January 2002 and June 2005. They found that the higher the

Table 2 Number of deaths and adjusted $\mathrm{HR}^{*}$ for patients with different level of socioeconomic deprivation (SED) in the Anhui cohort study, China

\begin{tabular}{|c|c|c|c|c|c|c|c|c|}
\hline Participants & $\begin{array}{l}\text { Number of } \\
\text { deaths/ } \\
\text { participants }\end{array}$ & $\begin{array}{l}\text { Mortality } \\
\text { rate }(\%) \dagger\end{array}$ & HR & $95 \% \mathrm{Cl}$ & p Value & $\begin{array}{l}\text { Ratio } \\
\text { of HR } ¥\end{array}$ & $95 \% \mathrm{Cl}$ & p Value \\
\hline $\begin{array}{l}\text { Patients without stroke } \\
\text { Patients with stroke }\end{array}$ & $501 / 2310$ & (3.7) & Ref & & & & & \\
\hline \multicolumn{9}{|l|}{ Educational level $^{\star}$} \\
\hline >Primary school & $18 / 64$ & $(6.0)$ & 1.26 & (0.78 to 2.06$)$ & 0.349 & Ref & & \\
\hline$\leq$ Primary school & $46 / 103$ & $(10.8)$ & 2.34 & (1.74 to 3.26$)$ & $<0.001$ & 1.88 & (1.05 to 3.36$)$ & 0.033 \\
\hline \multicolumn{9}{|l|}{ Occupational class* } \\
\hline Non-manual & $27 / 73$ & $(8.4)$ & 1.67 & (1.11 to 2.51$)$ & 0.013 & Ref & & \\
\hline Manual & $37 / 94$ & $(9.2)$ & 2.14 & (1.52 to 3.03 & $<0.001$ & 1.28 & (0.75 to 2.19$)$ & 0.359 \\
\hline \multicolumn{9}{|l|}{ Family income (¥/month)* } \\
\hline$\geq 1000$ & $31 / 94$ & $(7.4)$ & 1.52 & (1.04 to 2.23 ) & 0.030 & Ref & & \\
\hline$<1000$ & $33 / 73$ & $(10.7)$ & 2.50 & (1.73 to 3.60$)$ & $<0.001$ & 1.64 & (0.97 to 2.78$)$ & 0.067 \\
\hline \multicolumn{9}{|l|}{ Rural/urban living ${ }^{*}$} \\
\hline Urban & $37 / 103$ & (8.2) & 1.63 & (1.15 to 2.32 ) & 0.006 & Ref & & \\
\hline Rural & $27 / 64$ & $(10.0)$ & 2.47 & (1.65 to 3.69 ) & $<0.001$ & 1.51 & (0.88 to 2.57 ) & 0.131 \\
\hline
\end{tabular}


Table 3 Characteristics and outcomes of studies of mortality among people after stroke in China

\section{First author, (study years \\ and place) \\ SED measured \\ Stroke diagnosis criteria and patients selected}

Patients' characteristics

rate

Adjustment and outcome

Rural-urban only

$\mathrm{Wu}^{16}$

Used the WHO-MONICA stroke

(January 1984-December diagnosis criteria, excluding patients with

1993, Beijing region) TIA and chronic cerebrovascular death

Targeted about 700000 residents (including $1 / 3$ peasants)

Data collection on stroke cases was from a 3-degree monitoring network for register

Sun $^{17}$

Used the WHO-MONICA stroke

(January 1984-December diagnosis criteria, excluding patients with 2000 , Beijing region) TIA and chronic cerebrovascular death Based on the Sino-MONICA project of 1984-1993, including 200000 of 700000 residents; and within this population further survey data were collected until 2000

Educational level only Liu $^{18}$ Used 9th ICD and CT/MRI for diagnosis 846 patients with stroke were admitted to

(January-June 2005, Xijing hospital-a medical the hospital between January 2002 and university teaching hospital, Xi'an city, June 2005

Shanxi province)

Excluded patients with TIA/SAH, and those with serious disease of cancer, blood disorder, collagen disease, serious diseases of heart, lung, liver or kidney 485 patients with ischaemic stroke were left for investigation
Age range of 25-74 years including number of patients with stroke

year mortality from register data A $5 \%$ of the sampled population showed that average missing rate for registration was about $6-8 \%$

Age range of 35-74 years 13566 patients with strok were identified, including 9398 first-ever stroke $40.5 \%$ aged $65-74,59.3 \%$ men, and $79.8 \%$ urban

Averaged age 67.7 (SD 7.3), (range 60-93). $66.2 \%$ of men. All cases were ischaemic stroke selected 1 day, maximum 47 months. 37 patients $(7.6 \%)$ were lost to

follow-up

By phone/postcommunication to fill in the MRS form No more data available,
Age-standardised annual mortality (\%) in patients with stroke

Mortality rate (\%) in rural versus urban areas

Year Men Women

$1984 \quad 46.0$ vs $38.3 \quad 42.6$ vs 43.6

$1985 \quad 40.8$ vs $33.8 \quad 43.2$ vs 40.5

$1986 \quad 28.6$ vs $30.0 \quad 42.9$ vs 39.0

$1987 \quad 34.8$ vs $31.7 \quad 38.0$ vs 40.5

$1988 \quad 45.1$ vs $28.0 \quad 32.1$ vs 35.2

$1989 \quad 33.1$ vs $25.5 \quad 34.8$ vs 26.7

$1990 \quad 39.0$ vs $27.8 \quad 38.7$ vs 32.0

199146.0 vs $31.5 \quad 42.3$ vs 29.2

$1992 \quad 42.3$ vs $26.2 \quad 41.9$ vs 24.7

$1993 \quad 34.9$ vs $26.7 \quad 39.2$ vs 27.8

Both sex data showed a significant increase in mortality in rural versus urban (both $p<0.01$ )

Age-standardised mortality of stroke in rural areas was $38.7 \%$ and $26.3 \%$ in urban areas, $p<0.001$
Poor prognosis patients $(n=250)$ including 76 deaths and others with MRS $3-5$ scores compared with those with good prognosis $(n=235)$ having MRS $0-2$ scores

A stepwise regression analysis, including age, NIHSS score, history of stroke and educational level showed a coefficient of -0.042 (SE

$0.018), p=0.019$ for a continuous variable of educational level

Based on their original data of educational level, a crude RR for the poor prognosis could be calculated as 1.30 (95\% 1.10 to 1.54) in patients with $\leq$ primary school 
Table 3 Continued

First author, (study years

and place)

SED measured

selected

rate

come only

Sheng ${ }^{19}$

(January 2001-

December 2003, Zupi

Country Hospital, Henan

province)

Used the Chinese 3rd revision stroke diagnosis, including using CT/MRI.

Excluded patients with TIA/SAH, and those with serious disease of heart,

lung, liver and kidney

Recruited 143 patients

Multiple SED indicators Zhou $^{20}$

(August 1999-August 2002, Jingling Hospital, Nanjing city, Jiangsu province)

13.8), (range 32-88). 66.4\%
Patients' characteristics
Used CT/MRI for diagnosis

The Nanjing Stroke Registry Program, serving the residents of Nanjing city 2200 patients with first-ever stroke were identified

After excluding 624 haemorrhages or stroke and 770 who did not have CT/

MRI scans, 806 patients with ischaemic stroke were left for investigation
Averaged age 62.7 (SD of men. $67.1 \%$ of ischaemic stroke

131 patients followed up to 60 months (8.4\% lost to follow-up) Vital status-not saying how to follow-up

Averaged age 71.0 (SD . $68.1 \%$ date of stroke occurring to the date of men. All cases were ischaemic stroke selected of death from any cause within 3 years after stroke No lost to follow-up

\section{Adjustment and outcome}

\section{1 deaths}

In a univariate Cox regression, HR for patients with $<¥ 1000$ vs $\geq ¥ 1000$ per month was 1.57 (95\% Cl 1.50 to 1.65$), p=0.041$ )

In stepwise multivariate modelling, including age, injured brain tissues, shift, recurrence, discharge status and social support, the income variable was not selected for the analysis due to its significance level

166 deaths

After adjusted for age, sex, smoking, hypertension, diabetes mellitus,

hypercholesterolemia, martial fibrillation, myocardial infarction, prior TIA and NHISS,

HR was presented as follows:

1. Educational level

University degree $=1.00$

Technical college/training 1.81 (0.62 to 5.28 ) High secondary school 0.96 (0.33 to 2.78)

Secondary school 0.70 (0.28 to 1.77$)$

Primary school 0.97 (0.39 to 2.40 )

Illiteracy 0.79 (0.31 to 2.01)

2. Occupation class

Non-manual worker: 1.00

Manual worker: 5.18 (2.84 to 9.44$)(p<0.001)$

Unemployed: 5.77 (2.67 to 12.46$)(p<0.001)$

3. monthly income

$\geq ¥ 1000$ * $\mathrm{HR}=1.00$

$¥ 1-¥ 1000: 2.22$ (1.34 to 3.66 )

No income: 5.45 (3.18 to 9.34 )

4. Housing space

In $\geq 40 \mathrm{~m}^{2} /$ person, $\mathrm{HR}=1.00$

In 20-40 $\mathrm{m}^{2} /$ person, 1.52 (1.01 to 2.28 )

In $10-20 \mathrm{~m}^{2} /$ person, 1.17 (0.77 to 1.77 )

In $<10 \mathrm{~m}^{2} /$ person, 2.13 (1.23 to 3.70 )

*Currency exchange rate in 2011: China currency $¥ 10=$ US\$1.5881.

ICD, International Classification of Diseases; MRS, Modified Rankin Scale; NIHSS, National Institutes of Health Stroke Scale; RR, relative risk; SAH, subarachnoid hemorrhage; SED, socioeconomic deprivation; TIA, transient ischaemic attack. 
educational level (from illiteracy to polytechnic/university), the better the prognosis (Modified Rankin Scale (MRS) 0-2 scores versus MRS 3-5 scores or death) (table 3). These two studies included only a single indicator of SED measurements. The latter included outcomes of mortality combined with MRS, which prevented pooling data with other studies.

In the Nanjing Stroke Registry Program study of 19992002, Zhou et $a l^{20}$ followed up the vital status of 806 patients with first-ever ischaemic stroke for 3 years. After adjustment for patients' sociodemography, CVD risk factors and stroke severity, they found that high mortality was significantly associated with lower levels of occupational class, income and housing space, but not with educational level (table 3).

In the meta-analysis we included the Anhui cohort findings and any available data from three studies by Sheng et $a l^{19}$ Sun et $a l^{17}$ and Zhou et $a l^{20}$ The total number of patients involved was 14672 . Based on available data from Sun's study ${ }^{17}$ for mortality risk in rural versus urban patients, which was calculated based on numbers of deaths from mortality rates and the current Anhui cohort study, we found a significant increase in mortality after stroke in rural areas (a pooling RR of 1.47 (95\% CI 1.37 to 1.58) compared to urban areas. Using data from Zhou's study, ${ }^{20}$ where we re-calculated a RR of mortality of 4.66 (3.71 to $5.85)$ in patients with educational level of less than or equal to primary school versus those educated at more than primary school and the Anhui cohort study, we found that patients with stroke with low level of education had a higher mortality than their counterparts with high education (the pooled RR 3.07, 1.27 to 7.45). The pooled RR for mortality in patients with low income of $<¥ 1000$ per month was 1.58 (1.50 to 1.65 ), which was pooled from the Anhui cohort study, Sheng et al's study ${ }^{19}$ and Zhou et al's study. ${ }^{20}$ However, the pooled data from the Anhui cohort study and Zhou et al's study ${ }^{20}$ showed no statistical significances in mortality between patients with stroke with low and high occupational class; a RR of 2.56 (0.65 to 10.1) in manual workers versus non-manual workers.

\section{DISCUSSION}

The current study, comprising of a new cohort of patients with stroke and a systematic literature review has shown that survival after stroke is inversely associated with SED in China. The impact of SED on survival after stroke is substantial; around half of patients with stroke were in SED, and they had an approximately double risk of mortality compared to those without SED. The magnitude of the impact of SED on mortality after stroke in China is greater than that in high-income countries. ${ }^{3} 21$

\section{Strengths and weaknesses of the study}

The main contribution of this study lies in what it tells us about the impact of SED on survival after stroke in China-the most populous nation with the largest number of patients with stroke in the world. We used various indicators of SED to examine its association with mortality among patients with stroke in the Anhui cohort study. We employed a systematic literature review and a meta-analysis to determine the impact of SED on survival after stroke, the findings of which could be generable in China. Our data would increase knowledge about inequality in stroke survival in LMICs, which has largely been missed, ${ }^{2}$ and help tackle stroke survival inequality across the world. However, our study has limitations. First, the number of studies examining the association of SED with survival after stroke in China was not large, and data that could be utilised for meta-analysis were limited, particularly when pooling data based on each of the SED indicators. Second, in the Anhui cohort, approximately $10 \%$ of participants were lost to follow-up, which may introduce bias. ${ }^{7}$ However, there were no significant differences in the baseline characteristics of participants followed up and those lost to follow-up, except for more women, never smokers and widows being less likely to be followed up. ${ }^{7}$ Female gender was related to lifetime non-smoking and widowed status at baseline. In China, older mothers are more likely to live with their married daughter/son, particularly when they become widowed. Generally, they move to a daughter or son's house and help out; for example, the mother will look after the grandchildren while her daughter or son takes care of the mother's health. We do not know whether this would bring any bias to our Anhui cohort study results, but it seems minimal. As adjustments were made for gender, marital status and smoking history in the analysis, we do not think that the directional bias is significant in terms of the impact of SED on survival in patients with stroke. Although patients with stroke from wave 1 survey were prevalent, 42 incident patients with stroke showed similar results, which were, however, not significant due to the small number of patients. Third, in the Anhui data analysis we could not include stroke severity for adjustment. However, we adjusted for depression and dementia, which are related to the severity of stroke, ${ }^{22}$ and the residual effect of stroke severity on the association of SED with stroke survival would be minimal. Fourth, we lack data regarding stroke subtypes-thus we were unable to examine the association between SED and mortality in patients with haemorrhage stroke.

Recent data from a large-scale population-based stroke registry study in England showed a weak but significant association between SED and stroke survival; $17 \%$ of patients with stroke who were defined as having SED had an approximately $10-20 \%$ increased risk of mortality in short-term and long-term follow-up. ${ }^{3}$ The current study has identified that in China, about half of patients with stroke are in SED, and have a $>50 \%$ increase in mortality compared to those without SED. This survival inequality is greater than in England.

Over the last three decades, China has experienced economic and health transitions, with an increasing gap in income between rich and poor. Previously, we 
identified an increased risk of undetected neuropsychiatric illness among people with SED, suggesting that the low levels of access to healthcare and services could play an important role. ${ }^{23}$ In the current study of pooling all published data, we have found that, following a stroke, rural Chinese patients had a $50 \%$ increase in mortality compared with their urban counterparts. Wu et $a l^{16}$ reported that stroke care improved over time in urban areas in China, in terms of rates of admission to hospital and access to CT scanning, but it remained poor in rural areas. This may help explain a secular trend for increasing RR of mortality among rural versus urban patients in China. $^{16}$

Despite the inequality in survival after stroke, we did not observe participants without SED having a reduced incidence of stroke compared to those who had SED in the Anhui cohort. The preliminary data analysis showed no differences in the risk of stroke across different SED groups (see online supplementary table 2). This may reflect the fact that older adults in China, even with high socioeconomic status, had the same high risk of stroke as those with SED. It may raise the point that participants who had relatively high levels of education, occupational class and income and lived in urban areas did not have a lower level of CVD risk factors than their counterparts who were in SED. More attention to the prevention of stroke needs to be paid to the whole population of older adults in China.

In conclusion, there is a significant inverse association between SED and survival after stroke in China. The magnitude of the association is greater than that in highincome countries. Having low levels of education and income and living in rural areas have all played an important role in this association. To reduce survival inequality, the government needs to further reform the medical care system, with more capital being invested in people with SED and in rural residents. Innovative primary and secondary care strategies targeting people in low socioeconomic groups are required, along with effective measures to promote the uptake of effective stroke interventions and care in lower socioeconomic groups. Increasing the educational level and introduction of new stroke care systems from high-income countries, with evidence-based stroke services, will help improve survival in people with stroke.

\section{Author affiliations \\ ${ }^{1}$ School of Health Administration, Anhui Medical University, Hefei, China \\ ${ }^{2}$ Centre for Health and Social Care Improvement (CHSCl), Faculty of Education, Health and Wellbeing, University of Wolverhampton, UK ${ }^{3}$ Institute for Science and Technology in Medicine, Keele University, Keele, UK ${ }^{4}$ Department of Practice and Policy, School of Pharmacy, University College London, UK}

Acknowledgements The authors thank the participants and all who were involved in the Anhui cohort study. DZ was supported by the Strategic Research Development Fund, University of Wolverhampton, to complete her postdoctoral study in the Centre for Health and Social Care Improvement (CHSCl), University of Wolverhampton, UK. RC thanks Alzheimer"s Research, UK for providing a research grant (ART/PPG2007B/2) for the Research
Programme of Dementia in older people in China, which also helped the follow-up data collection in the Anhui cohort study. The authors appreciate Ms Amanda Rondey in $\mathrm{CHSCl}$ for editing the manuscript.

Contributors $\mathrm{RC}$ designed the study and wrote the first version of the paper. RC, LW, DZ, R-LC, LX, JW and ZH performed the statistical analysis and reviewed the literature. All co-investigators interpreted the results and revised the manuscript.

Funding The baseline data collection of the Anhui cohort study was supported by a research grant from The Royal Society, UK (Grant No. 574006.G603/22085), and the follow-up work by the BUPA Foundation, UK (Grants Nos. 45NOV06 and TBF-M09-05) and Anhui Province Natural Science Fund, China.

Competing interests None.

Patient consent Obtained.

Ethics approval Anhui Medical University, China.

Provenance and peer review Not commissioned; externally peer reviewed.

Data sharing statement No additional data are available.

Open Access This is an Open Access article distributed in accordance with the Creative Commons Attribution Non Commercial (CC BY-NC 4.0) license, which permits others to distribute, remix, adapt, build upon this work noncommercially, and license their derivative works on different terms, provided the original work is properly cited and the use is non-commercial. See: http:// creativecommons.org/licenses/by-nc/4.0/

\section{REFERENCES}

1. [No authors listed]. Tackling the global burden of stroke. Lancet Neurol 2005;4:689.

2. Addo J, Ayerbe L, Mohan KM, et al. Socioeconomic status and stroke: an updated review. Stroke 2012;43:1186-91.

3. Chen R, McKevitt C, Rudd AG, et al. Socioeconomic deprivation and survival after stroke: findings from the prospective South London Stroke Register of 1995 to 2011. Stroke 2014;45:217-23.

4. Woo J, Kwok T, Sze FK, et al. Ageing in China: health and social consequences and responses. Int J Epidemiol 2002;31:772-5.

5. Chen R, Hu Z, Qin X, et al. A community-based study of depression in older people in Hefei, China-the GMS-AGECAT prevalence, case validation and socio-economic correlates. Int J Geriatr Psychiatry 2004;19:407-13.

6. Chen R, Wei L, Hu Z, et al. Depression in older people in rural China. Arch Intern Med 2005;165:2019-25.

7. Chen R, Hu Z, Wei L, et al. Socioeconomic status and survival among older adults with dementia and depression. Br J Psychiatry 2014;204:436-40.

8. Chen R, Hu Z, Wei L, et al. Is the relationship between syndromes of depression and dementia temporal? The MRC-ALPHA and Hefei-China studies. Psychol Med 2009;39:425-30.

9. Chen R, Tunstall-Pedoe H. Socioeconomic deprivation and waist circumference in men and women: the Scottish MONICA surveys 1989-1995. Eur J Epidemiol 2005;20:141-7.

10. Engstad T, Bonaa KH, Viitanen M. Validity of self-reported stroke: the Tromso Study. Stroke 2000;31:1602-7.

11. Altman DG, Bland JM. Interaction revisited: the difference between two estimates. BMJ 2003;326:219.

12. Zhang $\mathrm{XH}$, Guan T, Mao J, et al. Disparity and its time trends in stroke mortality between urban and rural populations in China 1987 to 2001: changing patterns and their implications for public health policy. Stroke 2007;38:3139-44.

13. Chen R, Copeland JR, Wei L. A meta-analysis of epidemiological studies in depression of older people in the People's Republic of China. Int J Geriatr Psychiatry 1999;14:821-30.

14. Shah $A D$, Nicholas $O$, Timmis $A D$, et al. Threshold haemoglobin levels and the prognosis of stable coronary disease: two new cohorts and a systematic review and meta-analysis. PLoS Med 2011;8:e1000439.

15. Wells GA, Shea B, O'Conell D, et al. The Newcastle-Ottawa Scale for assessing the quality of nonrandomized studies in meta-analyses. 2014. http://www.ohri.ca/programs/clinical epidemiology/oxford.asp (accessed 10 Jul 2014). 
16. Wu GX, Wu ZS, Zeng ZS, et al. Epidemiology characteristics of stroke in Beijing (SINA-MONICA-Beijing Studies). J Heart Lung Blood Vessel Dis (Chin) 1998;17:252-5.

17. Sun JY, Zhao D, Wang W, et al. [The changing case-fatality of acute stroke in Beijing during 1984 to 2000]. Zhonghua Nei Ke Za Zhi 2007;46:362-5.

18. Liu XD, Lu YL, Wang B, et al. A study of prognosis and influential factors of ischemic stroke in the elderly. Chin J Geriatr Heart Brain Vessel Dis 2010;9:240-3.

19. Sheng XP, Qiu GF, Chen WN, et al. A 5-year follow-up cohort study of survival in stroke patients. J Mil Surg Southwest China 2010;12:247-9.
20. Zhou G, Liu X, Xu G, et al. The effect of socioeconomic status on three-year mortality after first-ever ischemic stroke in Nanjing, China. BMC Public Health 2006;6:227.

21. Kapral MK, Fang J, Chan C, et al. Neighborhood income and stroke care and outcomes. Neurology 2012;79:1200-7.

22. Ayerbe L, Ayis S, Rudd AG, et al. Natural history, predictors, and associations of depression 5 years after stroke: the South London Stroke Register. Stroke 2011;42:1907-11.

23. Chen R, Hu Z, Chen RL, et al. Determinants for undetected dementia and late-life depression. Br J Psychiatry 2013; 203:203-8. 